\title{
Saving, Investment, and Economic Outlook
}

U though the pace of economic activity in recent months has been more moderate than in 1965 and early 1966 . Total demand for goods and services has been slowed by an inventory adjustment. However, final sales have advanced rapidly, upward pressures on prices have remained, and government actions, which usually affect the economy with a lag, have been expansionary.

The slowdown in activity followed previous advances which were not consistent with stable prices. Last fall and winter, households saved a larger prow portion of their incomes. This development apparently caught businessmen by suprise, and as a result there was a very rapid accumulation of inventories in the fourth quarter of last year. Adjustment of those inventory excesses has been undertaken during the first half of this year.

In addition to the decrease in inventory investments, investment in plant and equipment has declined. This combination of factors-whouseholds moreasing saving last winter, and businesses decreasing investment de-

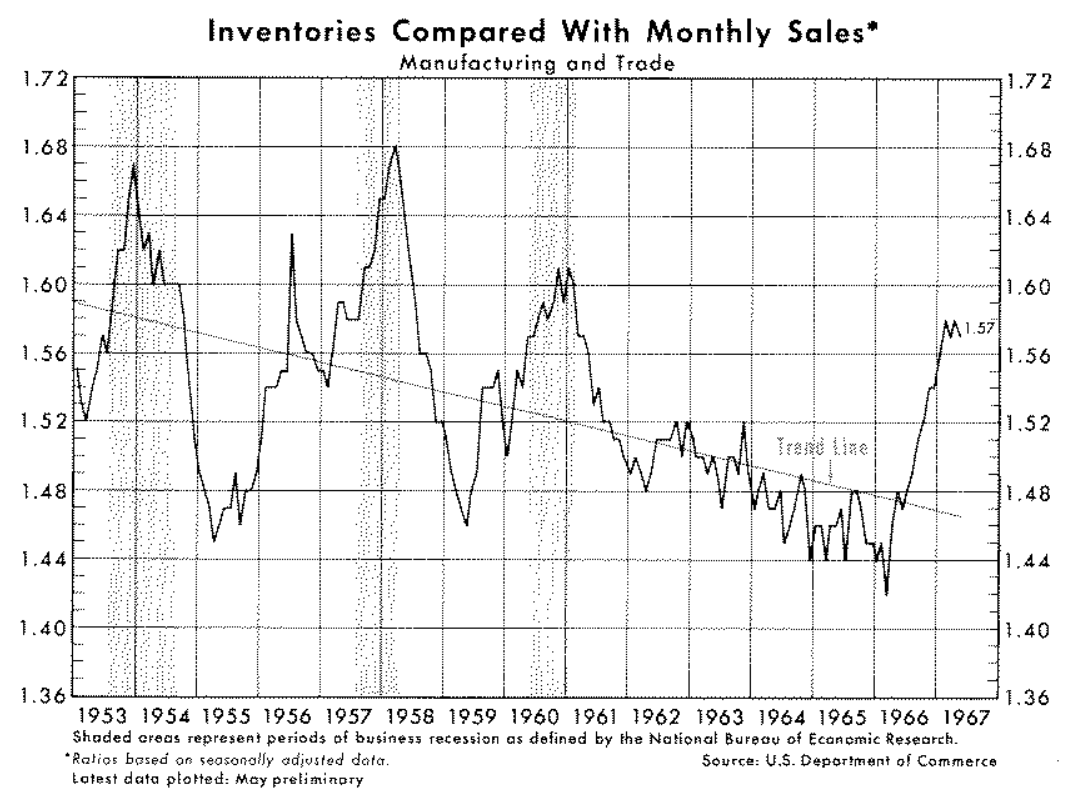

mand this spring and early summer-prompted the slowdown in aggregate economic activity relative to previous rates of advance. If it were not for the continuing expansive force of fiscal actions and the stimulative monetary moves in the first half of 1967, the slowdown would probably have been much more marked and severe.

The economic outlook for the rest of 1967 depends crucially on the relation between total desired saving (private plus Government) and investment plans. These plans are influenced to a considerable extent by monetary and fiscal developments, current and expected. But, in fact, the speed of response by private economic units to policy stimuli will be an important factor in determining economic developments in the near future.

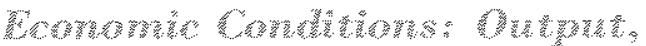

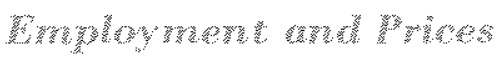

As of mid-1967, the economy appears to be poised for a resumption of the expansion of total demand which had continued almost without interruption from 1961 through 1966. Gross national product in current dollars rose at a 4 per cent annual rate from fourth quarter of 1966 to second quarter 1967 , following the extremely rapid 8 per cent average rate from 1964 to late 1966.

The slowdown in total dollar spending has been reflected in total real output; which in the second quarter was up at a 1 per cent rate from the fourth quarter of last year. The slowdown in the growth of real output in the first half of this year was a lagged response to the deceleration in growth of final sales (GNP minus change in business inventories) from a 10 per cent rate in 1965 , to a 7 per cent rate in mid-1966, to a 6 per cent rate in the fourth quarter of 1966. Final sales 


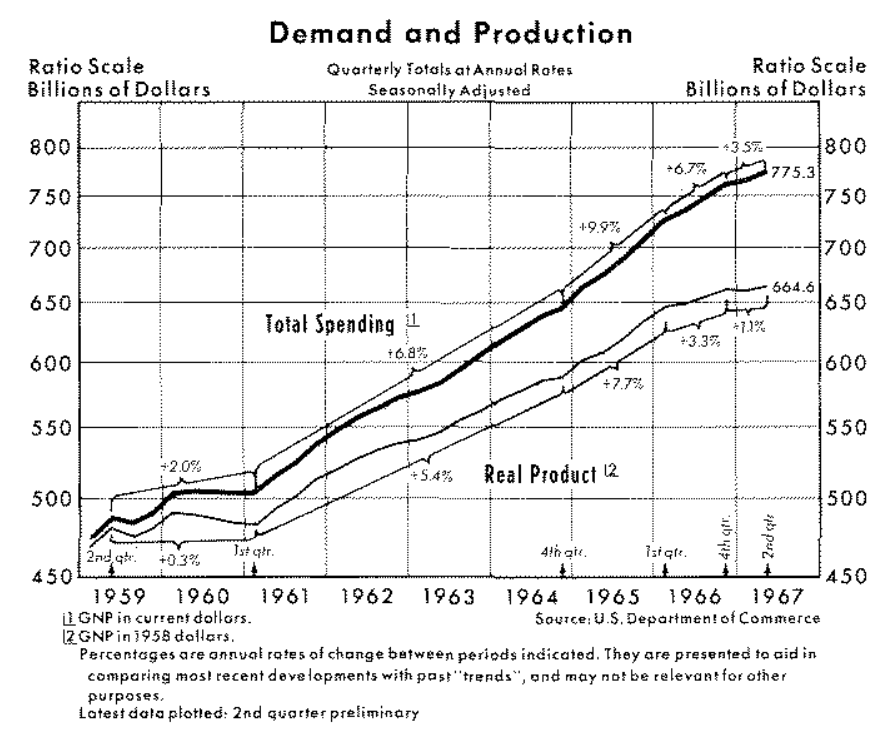

have surged upward again in 1967 at an 8 per cent rate, suggesting that total growth will soon follow.

Reffecting in part the acceleration of growth in final demand in the first half of 1967 , consumer prices on items other than food increased at an annual rate of 3.0 per cent. Food prices, which had been a factor tending to hold down overall consumer prices, increased in May and June.

Price increases accounted for all of the increase in GNP in the first quarter of this year, but in the second quarter real output resumed its advance, increasing at an annual rate of 2.4 per cent. This increase compares with an average annual rate of growth of 6 per cent during the period 1964-1966.

The slowdown in national economic activity has

Final Sales

Jotal Spendiatg Less Changes in Bessiness laventories

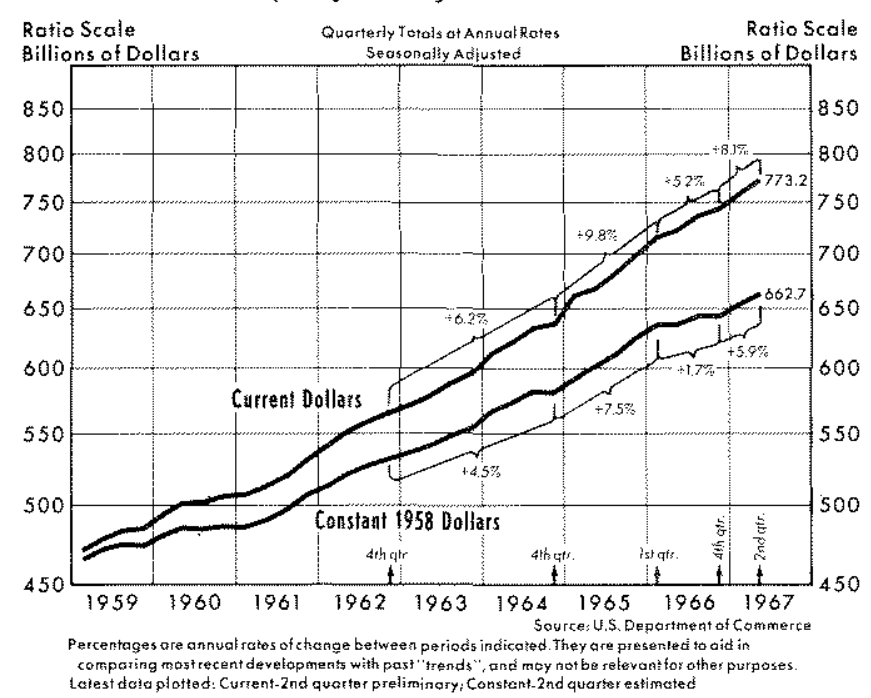

been chiefly in the manufacturing sector. Sales of durable goods, both to households and to businesses, slipped measurably. Industrial output declined at a 5 per cent annual rate from December 1966 to June 1967, after advancing at a 9 per cent average rate from 1964 to late 1966. Renewed strength in manufacturing has recently been indicated as new orders outpaced shipments in May and June, resulting in an increase of backlogs for the first time this year.

Total employment has risen moderately during the first half of 1967, and unemployment as a per cent of the labor force has increased slightly. There is some indication that the slowdown in production has been met primarily by reducing overtime rather than number of workers. Such a situation will permit a rapid adjustment to increased output once businessmen are convinced of the strength of final sales.

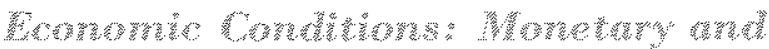

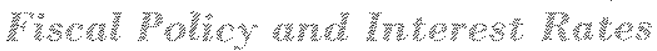

Monetary and credit developments have been very expansive in recent months. Rates of expansion of some monetary variables have been even more rapid than in the expansive period of late 1965 and early 1966. Federal Reserve credit has expanded at a 15 per cent annual rate since last December, compared with a 10 per cent average rate from 1964 to 1966 . Total member bank reserves have increased at a 10 per cent rate since December, substantially greater than the 4.5 per cent average rate from 1964 to 1966 . Commercial bank credit rose at a 13 per cent rate in the first half of the year, following a 9 per cent average rate of growth from 1964 to 1966 . Money stock grew

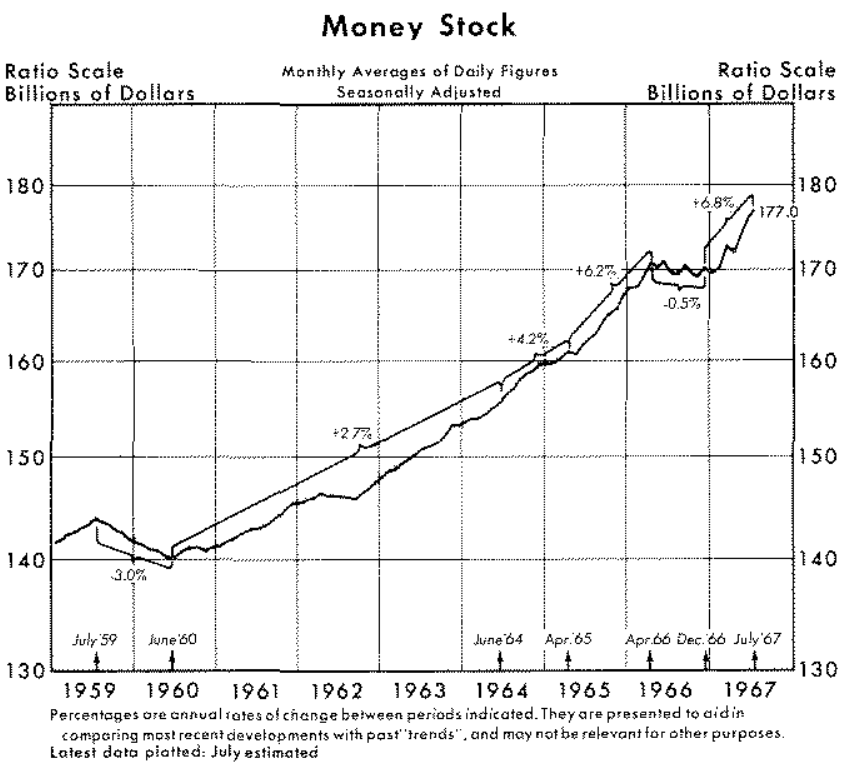


Interest Rates

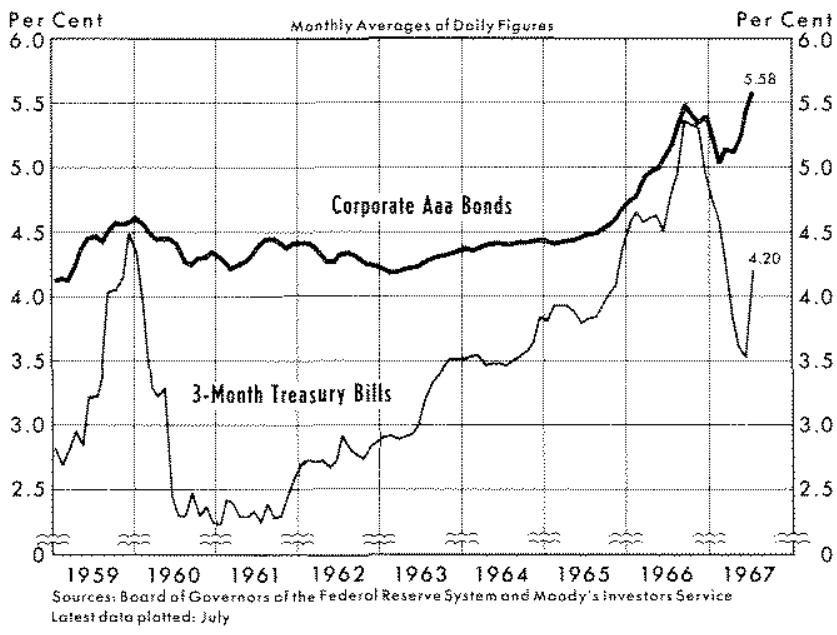

at about a 7 per cent annual rate in the last six months, considerably above the rapid 4 per cent average rate of expansion from 1964 to 1966.

Interest rates have risen despite the rise in bank credit. Demands for funds by businesses and government have been intense. The upward movement of long-term rates began early in the year. Short-term rates, which had generally declined since last summer, have increased markedly since mid-June.

The recent experience of rising interest rates at a time when money and credit were also rising is similar to the period from mid-1965 to the spring of 1966 when interest rates rose rapidly. In both cases interest rates rose as a result of a great demand for loan funds, or anticipations thereof, and in spite of large contributions to available credit supplies by the banking system. In both periods the Federal budget was exercising a strong upward infuence on interest rates.

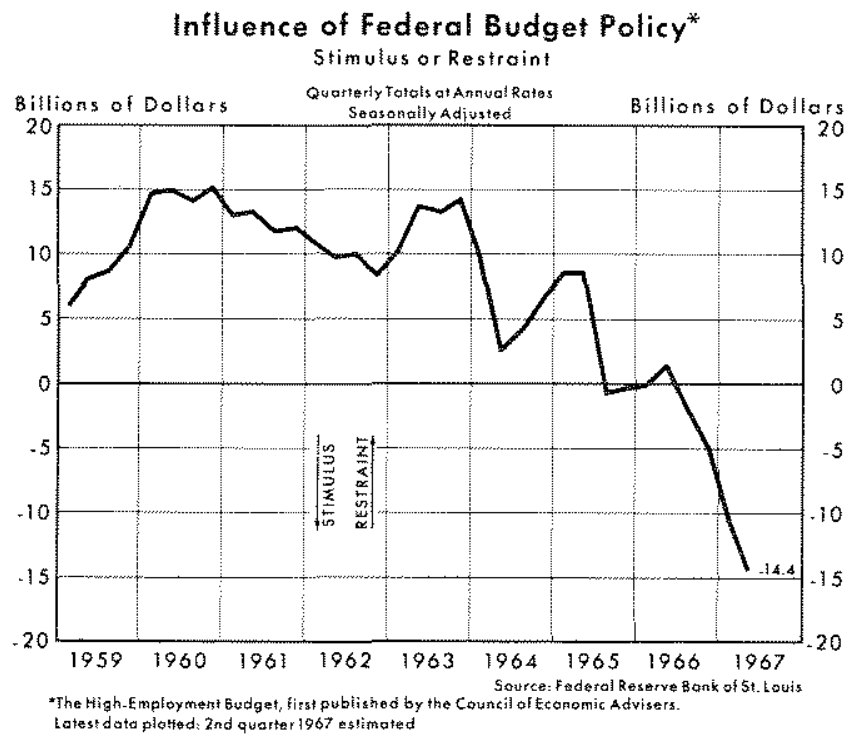

Influence of Federal Budget Policy* dy Totgls at Anaval Rat

Page 4
Government fiscal actions, which by historical standards were already highly stimulative from mid-1965 through 1966, became yet more expansionary in the first half of 1967. The high-employment budget, which adjusts the national income accounts budget for the effect of varying economic activity on tax receipts and on unemployment insurance disbursements, showed a $\$ 14$ billion deficit in the second quarter. This measure of fiscal actions was substantially in surplus from 1960 to mid-1965, and despite a shift toward stimulus in mid-1965, averaged a deficit of only $\$ 1.1$ billion from then through 1966.

Indications are that fiscal actions will remain stimulative for the rest of the year with or without adoption of the proposed 6 per cent tax surcharge. Rising defense spending and increased social security benefits are the main factors contributing to the outpacing of receipts by expenditures. The prospect of continuing Federal deficits portends stimulus to economic activity and continued upward pressure on interest rates.

\section{Sored \\ A

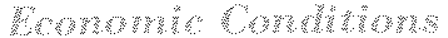

By focusing attention on the release of resources via saving (by both the private sector and govern ments), and the use of resources via investment (in plant, equipment, housing and inventory), it may be possible to isolate the dominant forces that caused the growth rate of GNP to slow in the first quarter of this year. Such an analysis may also give some insight into current and prospective developments. Such an approach has the advantage of bringing Federal fiscal actions directly into the analysis by interpreting the deficit or surplus as the net effect of Government on resource availibility.

In the national income accounts, the total amount saved by households, businesses, and governments must by definition equal the total amount invested, both domestically and abroad. The relevant forces in the determination of the level of spending and production, however, are the plans of savers and the plans of investors. If planned saving exceeds planned investment, spending and production tend to decrease. Such a situation indicates that investment is not absorbing all resources that are being released via saving. After the fact, the amount saved still equals the amount invested, as some savers accumulate less than anticipated because of declines in incomes, and some businesses invest more than expected as sales decrease and inventories rise. 
Economic developments in late 1966 and early 1967 suggest that saving plans were outpacing the investment plans of businesses. Such an inference raises a question as to whether this discrepancy reflects declines in investment plans, increases in saving plans, or both.

Data are not available on saving and investment plans, Economic data are after the fact, and need not coincide with intentions before the fact. Any inferences about planned magnitudes have to be derived indirectly from movements in observed data.

Household saving increased to abnormally high levels relative to disposable income in the fourth quarter of 1966 and the first quarter of 1967 . During short periods (say less than a year) saving is not systematically related to other economic variables such as incomes, interest rates, and wealth. One of the most volatile factors underlying personal saving is the portion of income that goes toward the purchase of consumer durables. Such expenditures are easily postponable and consumers vary substantially their purchases of autos, appliances and furniture over short periods, and their saving levels tend to vary inversely. There may be considerable stability and predicatability of consumer durable purchases over long periods, but such stability is of little help in analyzing economic developments within relatively short time periods.

Personal saving increased late last year but the specific cause is difficult to identify. Most economic factors generally thought to influence consumers were moving in a direction which usually causes them to increase outlays. Incomes were rising, interest rates were falling or stable, and wealth was increasing. One factor, however, may have been acting to restrain spending; money holdings had been declining relative to other assets since April, 1966, and consumers may have been attempting to restore a normal relationship by spending less of their income. Variability in saving (and spending) over short periods makes it difficult for businesses to forecast their sales, and thus inventory adjustments seem to be an inevitable part of a free market economy.
More recently, there is some evidence that consumer saving is declining. Consumer purchases of goods and services have been rising at a rate equal to or greater than personal incomes.

Business saving, retained earnings plus depreciation allowances, declined from mid-1966 to early 1967. This component of saving, however, should not be viewed in the same way as household saving. A rise or fall in business saving may result from either a change in the saving-investment plans of businesses, or from changes in the overall economic climate which affect the flow of funds into and out of businesses. Interpretation of changes in business saving depends greatly on which force was causal. Last winter, businesses invested heavily, apparently not by conscious decision, but because sales fell and inventories accumulated. Hence, this was a depressing factor on future activity, rather than the expansive force which typically accompanies a rise in investment plans. More recently, businesses have accumulated inventories at a slower pace and sales have risen.

Also included in total saving is that by the governments-Federal and state and local. State and local governments generally try to balance their budgets, and therefore state and local saving (or dissaving) does not vary substantially from quarter to quarter. In recent quarters state and local budgets have been slightly in surplus.

\section{OUTPUT, SPENDING AND SAVING}

Quarterly Totals af Seasonally Adjusted Annual Rates

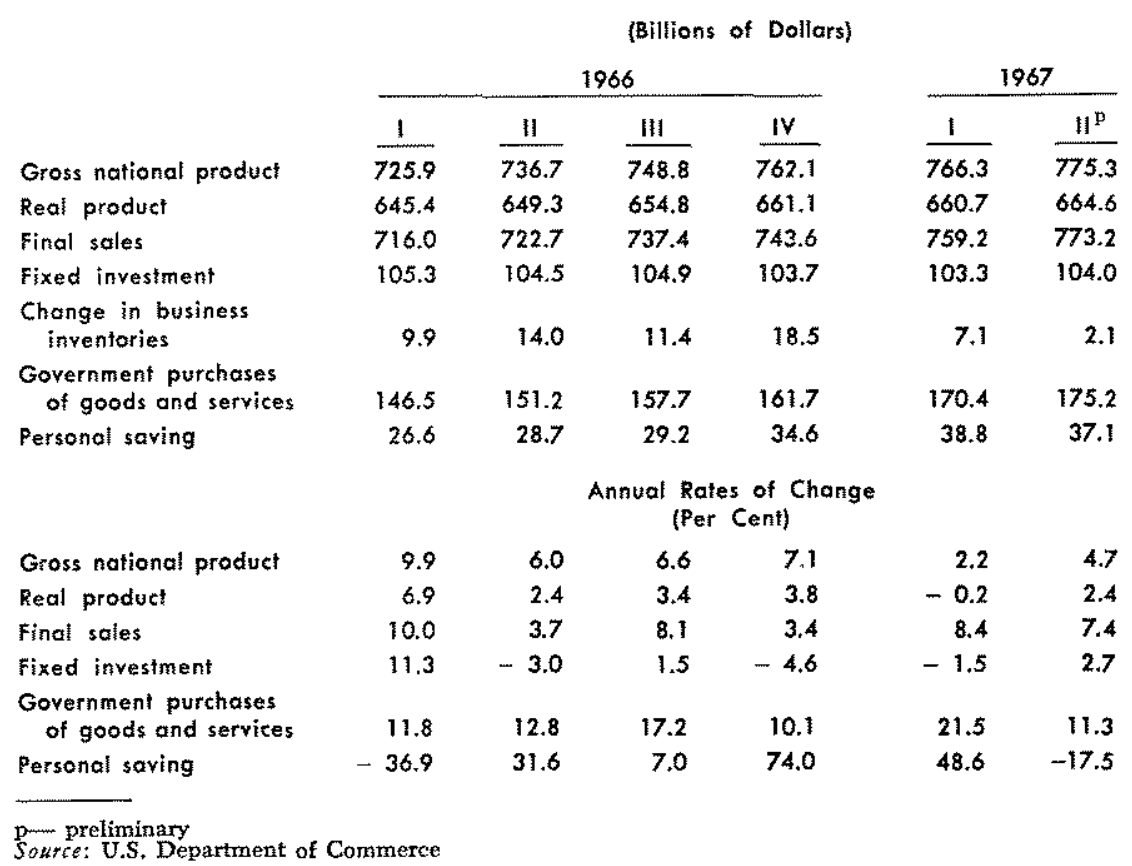


The amount of saving by the Federal Government, however, is of fundamental importance as a measure of Federal fiscal policy. The Federal surplus or deficit rises or falls with economic activity and, to this extent, does not indicate a discretionary decision to spend or save. Changes in the surplus or deficit caused by variations in Covernment spending or tax rates measure discretionary fiscal actions. An attempt to decompose the surplus or deficit into discretionary and passive effects is provided in the high-employment budget. This measure is normalized on fixed levels of economic activity and thereby abstracts the effect of changing economic activity on the budget surplus or deficit.

An enlarged Federal deficit (national income accounts basis) in late 1966 suggests a definite stimulus. A sharp increase in the deficit (negative saving) indicates a sharp increase in the demand by the Government for resources released by saving. In view of the slowdown in GNP growth, however, a part of this deficit reflects relatively sluggish activity rather than positive fiscal actions taken to expand GNP. The highemployment budget shows a measure of this expansionary force; a surplus of $\$ 3.5$ billion in the second quarter of 1966 had changed to a $\$ 10$ billion deficit a year later.

Recent data on investment, which may be viewed as demand for saving, reveals declines which are in contrast to recent increases in private saving. Gross private domestic investment rose only slightly in the second and third quarters of 1966, as the decline in housing offset most of the advance in business investment. The increase in investment in the fourth quarter was due to large, unexpected and apparently involuntary inventory accumulation. Businesses have been adjusting these levels during the first half of 1967, accounting for the sharply decreased investment in this period.

Attempts at meaningful interpretation of the savinginvestment data suggest the desirability of "highemployment" values for other magnitudes in addition to Government saving, that is, eliminating the changes in these magnitudes resulting merely from changes in overall economic activity. Proportions of GNP going to saving during periods of high-employment activity show that personal saving recently was above its high-employment average of past periods. The saving rate has more recently been falling, but the capricious consumer holds the key as to whether this trend will continue.

Investment as a proportion of GNP, on the other hand, is currently below its historical high-employment average. Investment can be expected to turn up in the near future as the inventory adjustment process is completed. Its upward movement, however, is contingent in part upon business expectations which will be influenced by consumer, business and Government actions.

This saving-investment analysis gives some support to the view that overall activity is apt to expand in the near future, but such a study does not lead to precise conclusions. What has happened in the past is known only after adjustments in the market place. Patterns of saving and investment intentions and behavior are not sufficiently predictable to indicate reliably the course of future developments. It is evident, however, that recent fiscal influence has been expansive, tending to offset a major part of the increase in the private saving rate and the decrease in investment demand.

It is also evident that the money stock has been rising sharply, and hence the desire to save in order to build up cash balances has been reduced. If these developments continue, and households decide to save less and spend more, it seems likely that total savings plans will fall short of investment.

The expansive monetary developments are also causing interest rates to be lower than they might otherwise be, and liquidty to be higher. To the extent that private investment and total private spending are responsive to this policy stimulus, investment can be expected to increase rather than decline in future quarters. Thus, it appears that on the basis of a cursory examination of the saving-investment data, expansionary forces are at work. To the extent that private economic units respond to policy stimuli with a lag, the problem in late 1967 and early 1968 could be one of excessive demands on resource utilization. 